\title{
What are the best predictors and management for a long-term clinical success after surgical AF ablation?
}

\author{
Shiro Nakahara \\ Department of Cardiology, Dokkyo Medical University Saitama Medical Center, Saitama, Japan \\ Correspondence to: Shiro Nakahara, MD, FACC. Department of Cardiology, Dokkyo Medical University Saitama Medical Center, 2-1-50 Minami \\ Koshigaya, Koshigaya, Saitama, Japan. Email: nshiro@dokkyomed.ac.jp. \\ Provenance: This is an invited Editorial commissioned by Executive Editor-in-Chief Jianxing He (Director of the Thoracic Surgery Department, The \\ First Affiliated Hospital of Guangzhou Medical University, Guangzhou, China). \\ Comment on: Ad N, Holmes SD. Early Stable Sinus Rhythm Associated With Greater Success 5 Years After Surgical Ablation. Ann Thorac Surg \\ 2018;105:1370-76.
}

Submitted Sep 01, 2018. Accepted for publication Sep 11, 2018.

doi: $10.21037 /$ jtd.2018.09.59

View this article at: http://dx.doi.org/10.21037/jtd.2018.09.59

Surgical ablation procedures have been performed for almost 30 years. Several observational studies have investigated the variables associated with a 'failure' of surgical ablation procedures for atrial fibrillation (AF). Those studies have demonstrated that an increased age, large left atrial diameter, the duration of AF are independent predictors of failure during the mid-term follow up after surgery (1-4). Further, recent studies have shown that early recurrence of arrhythmias after surgery is an important risk factor for a late failure $(5,6)$. However, the follow up period of those data is relatively short, and the evidence is particularly lacking for the prediction of the long-term success in order to develop a credible procedural and post-procedural management.

Radiofrequency catheter ablation has become a wellaccepted management procedure for AF. However, failure is not uncommon and almost two-thirds or less of the patients are free of AF at the long-term follow up $(7,8)$. It has been recognized that early recurrence of atrial tachyarrhythmias, defined as recurrence in the first 3 months following the procedure, may not always predict a recurrent arrhythmia later, however, other retrospective studies have demonstrated that early recurrent tachycardias are frequently associated with late recurrences of atrial arrhythmias $(9,10)$. Both surgical and catheter approaches for AF still have a question regarding the best long-term predictor for the clinical success after the procedure for the treatment of AF. In a study published in this issue of the Journal, Ad et al. addressed the question of the relationship between the risk factors and late recurrence in a prospectively designed study (11).

Previous papers reported that early recurrent tachycardias are common after catheter ablation procedures, occurring in as many as $16-65 \%$ of patients $(9,10,12-14)$. Similar findings were observed in patients who undergo surgical AF procedures (5). However, almost half of the patients with early recurrences after catheter-based ablation procedures are arrhythmia free during the long-term follow up $(9,10,12-14)$. These data suggest that the mechanism of early recurrences is considered to differ from that of late recurrences. Regarding early recurrences, injury of the acute myocardium and a subsequent inflammatory response, as well as the modification of the autonomic nervous tone, may create an early proarrhythmic substrate that alters the atrial conduction and refractoriness. Differing from the early recurrence mechanism, late recurrences are more likely to be attributable to reconnections of intra-atrial or atrial-pulmonary vein conduction and also the reactivation of arrhythmia substrates.

In this context, the study by Ad et al. in the issue of the Annals of Thoracic Surgery (11) is a welcome addition to the field. These investigators studied 743 patients with a surgical AF ablation and systematically examined the factors associated with a 1-year success and no arrhythmia recurrence during $1-5$ years after the surgery. They performed a precise statistical analysis and concluded that 
the majority of the patients with no detected arrhythmias throughout the first 12 months following surgical ablation continued to be recurrence-free for 5 years. Further, a younger age, shorter preoperative AF duration, and greater surgeon experience were associated with the maintenance of sinus rhythm. This is an important study and gives us insight into understanding the possible mechanisms of late recurrences in patients undergoing surgical $\mathrm{AF}$ ablation.

Importantly, this study reaffirms that both early and midterm failures are the predictors of a late recurrence during the long-term follow up. Predictors of early recurrence include not only markers of acute inflammation (fever heat, C-reactive protein, etc.) (15-17), but also conventional factors that predict a late recurrence. These include the procedural factors similar to the mid-term follow up, like non-isolated pulmonary veins (18) and the inability to terminate AF (19) after the procedure. This dichotomy theory of the risk factors of early recurrences implies that the acute and reversible procedure-related factors are only part of the pathogenic mechanism factors that are involved in early recurrences. There is a tendency for patients that eventually achieve a successful outcome only to have reversible factors. Further, patients with risks for late recurrences in which early recurrences occur are likely to have a late recurrence. This tangled recurrent mechanisms of the early and mid-term phases make it difficult to predict the long-term success by only spot ECG evaluations. Thus, it is conceivable that the confirmation of the continuous suppression of the recurrent arrhythmias for a certain period of time would enable finding the best long-term predictors for a clinical success after a surgical AF ablation.

The most notable limitation of this study was the implementation of inhomogeneous strategies for a surgical technique. That was based on each surgeon's discretion, and it was not clear how much left atrial "cut-and-sew" lesion sets and variable energy deliveries were required to create a transmural lesion. Further, the endpoint of the surgical approach was also unclear. If a uniformly designed surgical technique had been employed in all cases, then it would have provided more valuable information and evidence in this field.

An additional limitation was acknowledged by the investigators, and was the accurate detection of atrial tachyarrhythmias after the surgery. As authors stated, an ideal monitoring strategy has not been established because the current insertable cardiac monitors (ICMs) have a highrate of false-positive readings and limited storage space available on the ICM (20). Current guidelines recommend performing an ECG at each follow-up visit and at least 24-hour Holter monitoring once every 12 months for paroxysmal $\mathrm{AF}$ and every 6 months for persistent $\mathrm{AF}$ to document the freedom from AF (21). However, a number of investigators have concluded that continuous monitoring is more sensitive at detecting recurrent atrial tachyarrhythmia episodes (22-24). Although, the Cox-Maze procedure has a high reported success rate, a more accurate means of follow-up would allow for a better postoperative management. Recently an ICM device employing a new p-wave enhanced AF detection algorithm with a remote monitoring system has been developed, and a multicenter study that demonstrated an extremely high sensitivity in detecting the AF duration in patients with a history of intermittent and symptomatic PAF was performed (25). Reliable methods of arrhythmia detection after surgical AF ablation by a combination of a polished ICM algorithm and continuous wireless monitoring are needed to improve our understanding of the best long-term predictors for a clinical success after surgical AF ablation.

Overall, the results of this study revealed the concrete risk factors for late recurrences in patients who underwent surgical AF ablation. Early recurrence is not necessarily involved in failure during the late follow-up, but a certain degree of patients may have a significant recurrence in the late phase. For higher risk patients with early recurrence, such as those with an older age and longer preoperative $\mathrm{AF}$ duration, an aggressive attempt to maintain sinus rhythm, including cardioversion and reintervention, may be reasonable. Future studies should focus on the standardization of the surgical procedure, as well as a more tailored follow-up management in patients with a higher risk of recurrence to minimize the unnecessary provocation of the use of antiarrhythmic and anticoagulant medications.

\section{Acknowledgements}

None.

\section{Footnote}

Conflicts of Interest: The author has no conflicts of interest to declare.

\section{References}

1. Ad N, Cox JL. The Maze procedure for the treatment of atrial fibrillation: a minimally invasive approach. J Card 
Surg 2004;19:196-200.

2. Ad N, Henry L, Hunt S. The concomitant cryosurgical Cox-Maze procedure using Argon based cryoprobes: 12 month results. J Cardiovasc Surg (Torino) 2011;52:593-9.

3. Gillinov AM, Saltman AE. Ablation of atrial fibrillation with concomitant cardiac surgery. Semin Thorac Cardiovasc Surg 2007;19:25-32.

4. Damiano RJ Jr, Voeller RK. Surgical and minimally invasive ablation for atrial fibrillation. Curr Treat Options Cardiovasc Med 2006;8:371-6.

5. Ad N, Henry L, Holmes SD, et al. The association between early atrial arrhythmia and long-term return to sinus rhythm for patients following the Cox maze procedure for atrial fibrillation. Eur J Cardiothorac Surg 2013;44:295-300; discussion 300-1.

6. Damiano RJ Jr, Schwartz FH, Bailey MS, et al. The Cox maze IV procedure: predictors of late recurrence. J Thorac Cardiovasc Surg 2011;141:113-21.

7. Calkins H, Reynolds MR, Spector P, et al. Treatment of atrial fibrillation with antiarrhythmic drugs or radiofrequency ablation: two systematic literature reviews and meta-analyses. Circ Arrhythm Electrophysiol 2009;2:349-61.

8. Noheria A, Kumar A, Wylie JV Jr, et al. Catheter ablation vs antiarrhythmic drug therapy for atrial fibrillation: a systematic review. Arch Intern Med 2008;168:581-6.

9. Themistoclakis S, Schweikert RA, Saliba WI, et al. Clinical predictors and relationship between early and late atrial tachyarrhythmias after pulmonary vein antrum isolation. Heart Rhythm 2008;5:679-85.

10. Choi JI, Pak HN, Park JS, et al. Clinical significance of early recurrences of atrial tachycardia after atrial fibrillation ablation. J Cardiovasc Electrophysiol 2010;21:1331-7.

11. Ad N, Holmes SD. Early Stable Sinus Rhythm Associated With Greater Success 5 Years After Surgical Ablation. Ann Thorac Surg 2018;105:1370-6.

12. Andrade JG, Khairy P, Verma A, et al. Early recurrence of atrial tachyarrhythmias following radiofrequency catheter ablation of atrial fibrillation. Pacing Clin Electrophysiol 2012;35:106-16.

13. Andrade JG, Macle L, Khairy P, et al. Incidence and significance of early recurrences associated with different ablation strategies for AF: a STAR-AF substudy. J Cardiovasc Electrophysiol 2012;23:1295-301.

14. Joshi S, Choi AD, Kamath GS, et al. Prevalence, predictors, and prognosis of atrial fibrillation early after pulmonary vein isolation: findings from 3 months of continuous automatic ECG loop recordings. J Cardiovasc Electrophysiol 2009;20:1089-94.

15. Koyama T, Tada H, Sekiguchi Y, et al. Prevention of atrial fibrillation recurrence with corticosteroids after radiofrequency catheter ablation: a randomized controlled trial. J Am Coll Cardiol 2010;56:1463-72.

16. Koyama T, Sekiguchi Y, Tada H, et al. Comparison of characteristics and significance of immediate versus early versus no recurrence of atrial fibrillation after catheter ablation. Am J Cardiol 2009;103:1249-54.

17. Lellouche N, Sacher F, Wright M, et al. Usefulness of $\mathrm{C}$-reactive protein in predicting early and late recurrences after atrial fibrillation ablation. Europace 2009;11:662-4.

18. Bertaglia E, Stabile G, Senatore G, et al. Predictive value of early atrial tachyarrhythmias recurrence after circumferential anatomical pulmonary vein ablation. Pacing Clin Electrophysiol 2005;28:366-71.

19. Li XP, Dong JZ, Liu XP, et al. Predictive value of early recurrence and delayed cure after catheter ablation for patients with chronic atrial fibrillation. Circ J 2008;72:1125-9.

20. Damiano RJ Jr, Lawrance CP, Saint LL, et al. Detection of Atrial Fibrillation After Surgical Ablation: Conventional Versus Continuous Monitoring. Ann Thorac Surg 2016;101:42-7; discussion 47-8.

21. Calkins H, Kuck KH, Cappato R, et al. 2012 HRS/EHRA/ ECAS expert consensus statement on catheter and surgical ablation of atrial fibrillation: recommendations for patient selection, procedural techniques, patient management and follow-up, definitions, endpoints, and research trial design: a report of the Heart Rhythm Society (HRS) Task Force on Catheter and Surgical Ablation of Atrial Fibrillation. Developed in partnership with the European Heart Rhythm Association (EHRA), a registered branch of the European Society of Cardiology (ESC) and the European Cardiac Arrhythmia Society (ECAS); and in collaboration with the American College of Cardiology (ACC), American Heart Association (AHA), the Asia Pacific Heart Rhythm Society (APHRS), and the Society of Thoracic Surgeons (STS). Endorsed by the governing bodies of the American College of Cardiology Foundation, the American Heart Association, the European Cardiac Arrhythmia Society, the European Heart Rhythm Association, the Society of Thoracic Surgeons, the Asia Pacific Heart Rhythm Society, and the Heart Rhythm Society. Heart Rhythm 2012;9:632-96.e21.

22. Hindricks G, Pokushalov E, Urban L, et al. Performance of a new leadless implantable cardiac monitor in detecting 
and quantifying atrial fibrillation: Results of the XPECT trial. Circ Arrhythm Electrophysiol 2010;3:141-7.

23. Ziegler PD, Koehler JL, Mehra R. Comparison of continuous versus intermittent monitoring of atrial arrhythmias. Heart Rhythm 2006;3:1445-52.

24. Charitos EI, Stierle U, Ziegler PD, et al. A comprehensive evaluation of rhythm monitoring strategies for the detection of atrial fibrillation recurrence: insights from
647 continuously monitored patients and implications for monitoring after therapeutic interventions. Circulation 2012;126:806-14.

25. Sanders P, Purerfellner H, Pokushalov E, et al.

Performance of a new atrial fibrillation detection algorithm in a miniaturized insertable cardiac monitor: Results from the Reveal LINQ Usability Study. Heart Rhythm 2016;13:1425-30.

Cite this article as: Nakahara S. What are the best predictors and management for a long-term clinical success after surgical AF ablation? J Thorac Dis 2018;10(Suppl 33):S4006-S4009. doi: $10.21037 /$ jtd.2018.09.59 